\title{
The association between liver enzymes and risk of type 2 diabetes: the Namwon study
}

\author{
Hye-Ran Ahn', Min-Ho Shin ${ }^{1}$, Hae-Sung Nam², Kyeong-Soo Park ${ }^{3}$, Young-Hoon Lee ${ }^{4}$, Seul-Ki Jeong ${ }^{5}$, \\ Jin-Su Choi ${ }^{1}$ and Sun-Seog Kweon ${ }^{1 *}$
}

\begin{abstract}
Background: We examined the association between liver enzymes and development of type 2 diabetes in a general Korean population.

Methods: A total of 10,667 subjects (4,201 males and 6,466 females) aged 45 to 74 years participated in a baseline examination between 2004 and 2007. Among the subjects, 8,157 (3,231 males and 4,926 females) underwent follow-up examination from 2007 to 2011, for a median follow-up period of 4.2 years. Type 2 diabetes was defined as intake of anti-diabetic agents, insulin treatment, fasting glucose concentration of more than $126 \mathrm{mg} / \mathrm{dl}$, or hemoglobin A1c of more than $6.5 \%$ at re-examination. Associations of liver enzymes with incidence of type 2 diabetes were analyzed using logistic regression models.

Results: During the follow-up period, 548 subjects (235 males, 313 females) developed type 2 diabetes. After adjusting for comprehensive diabetes risk factor, the risk of type 2 diabetes was significantly higher in the highest alanine aminotransferase (ALT) quartile than in the lowest quartile (odds ratio (OR): 1.95, 95\% confidence interval (CI): 1.18-3.21 in males; OR: 1.49, 95\% Cl: 1.03-2.16 in females). Similar results were observed for gammaglutamyltransferase (GGT) quartiles, but in the fully adjusted analysis, the OR for the highest versus lowest quartiles was significant only for females (OR: 1.58, 95\% Cl: 0.95-2.63 in males; OR: 1.85, 95\% Cl: 1.23-2.79 in females).
\end{abstract}

Conclusions: Our results suggest that serum ALT concentrations were independently associated with type 2 diabetes in both sexes, and that GGT was also independently associated but only in females.

Keywords: Chronic disease, Diabetes, Epidemiology

\section{Background}

The liver plays an important role in maintenance of normal glucose levels during fasting as well as in the postprandial period [1], and its role in the pathogenesis of type 2 diabetes has attracted much interest. Indeed, hepatic dysfunction resulting from insulin-resistance syndrome may lead to development of type 2 diabetes [2].

The liver enzymes, aspartate aminotransferase (AST), alanine aminotransferase (ALT), and gammaglutamyltransferase (GGT), are routinely used in evaluation of liver function. Aspartate aminotransferase (AST) and ALT are considered markers of hepatocellular health, whereas GGT also indicates biliary tract function. Alanine

\footnotetext{
* Correspondence: ujingogo@paran.com

'Department of Preventive Medicine, Chonnam National University Medical School, 5, Hak-dong, Dong-gu, Gwangju 501-746, Korea

Full list of author information is available at the end of the article
}

aminotransferase (ALT) is the most specific marker of liver pathology and is found primarily in this organ [3]. AST and GGT are also found in other tissues and are therefore less specific markers of liver function [4]. Although GGT is a less specific marker of liver function, higher GGT levels have been found to be an independent predictor of the incidence of type 2 diabetes.

A number of prospective studies have examined the associations between concentrations of AST [5-12], ALT [5-11,13,14], or GGT [3,4,6-11,14-21] and the incidence of type 2 diabetes. A few studies have examined the association of serum AST with risk for type 2 diabetes; two of these reported a significant association between serum AST and diabetes after adjustment for potential confounders [5,9]. Most previous studies examining the association between liver enzymes and incidence of type 2 diabetes have included only ALT or GGT. A limited 
number of prospective studies have examined the associations of AST, ALT, and GGT with risk of type 2 diabetes [6-14]; however, the results were inconsistent.

The purpose of this study was to examine the associations of serum liver enzyme (AST, ALT, and GGT) levels on the incidence of type 2 diabetes in a communitybased prospective cohort study of Korean individuals aged 45 to 74 years.

\section{Methods}

\section{Study population}

Data were derived from the Namwon Study [22]. The Namwon Study is a prospective, population-based cohort study conducted in the city of Namwon, Jeollabukdo, Korea. The study targets cardiovascular disease, osteoporosis, and dementia in elderly Koreans. The 2005 population census performed by the Korean National Statistics Office reported 33,068 residents (14,960 males and 18,108 females) aged 45-74 in Namwon city. From 2004 to 2007, all eligible residents aged 45-74 were invited to participate by mail and telephone, based on the list of officially registered residents. A total of 10,667 subjects (4,201 males and 6,466 females; response rate $32.3 \%)$ underwent clinical examinations following questionnaire interviews.

Of the 10,667 subjects, 8,157 (3,231 males and 4,926 females; response rate $76.6 \%$ ) participated in follow-up examinations between 2007 and 2011. Follow-up examinations were conducted using the same protocol as the baseline study. Of these 8,157 subjects, 1,231 (15.1\%) were excluded: 935 (11.5\%) subjects with type 2 diabetes at baseline examination; $146(1.8 \%)$ subjects who were diagnosed by physicians with chronic hepatitis B or C, liver cirrhosis, or liver cancer; 89 (1.1\%) subjects with incomplete data on any of the covariables; and $61(0.7 \%)$ subjects without a blood sample at baseline or followup examination. Finally, the prospective analysis included 6,926 subjects (2,603 males and 4,323 females) aged 45-74 years at baseline examination. Incidence of type 2 diabetes was identified as intake of anti-diabetic agents, receiving insulin treatment, fasting glucose levels $\geq 126 \mathrm{mg} / \mathrm{dl}$, or hemoglobin A1c levels $\geq 6.5 \%$ at follow-up examination.

\section{Baseline assessment}

All subjects underwent a clinical examination and answered a questionnaire, which included questions on lifestyle, medical history (including diabetes, hypertension, and other chronic diseases), and medical treatment with insulin and oral anti-diabetic agents.

Subjects were classified into three groups according to their alcohol intake status: nondrinkers, ex-drinkers, and current drinkers. Subjects were characterized on the basis of smoking status as never smokers, ex-smokers, and current smokers. Physical activity was classified into two categories according to whether subjects reported engaging in any physical activity, such as jogging, bicycling, swimming, or climbing.

Trained medical personnel performed anthropometric measurements. Body mass index (BMI), calculated as weight divided by the squared height in meters, was used as an index of relative weight. Waist circumference (WC) was measured to the nearest $0.1 \mathrm{~cm}$ using a tapeline. Blood samples were obtained from an antecubital vein in the morning after a 12-h overnight fast. Serum was separated on site within $30 \mathrm{~min}$ and was stored at $-70^{\circ} \mathrm{C}$ until analysis. AST, ALT, GGT, total cholesterol (TC), highdensity lipoprotein cholesterol (HDL-C), and triglycerides (TG) levels were measured by an automatic analyzer (HITACHI-7600, Hitachi, Japan). The HbA1c levels were analyzed by high-performance liquid chromatography (HPLC) using the VARIANT II system (Bio-Rad, Hercules, CA, USA). Serum C-reactive protein (CRP) was measured by latex-enhanced nephelometry by highsensitivity assays on the Behring Nephelometer II analyzer (Dade-Behring Diagnostics, Marburg, Germany). The index of insulin resistance was calculated on the basis of fasting values of plasma glucose and insulin, according to the homeostasis model assessment (HOMA) method [23], as insulin resistance $(\%)=$ [insulin (units/ $\mathrm{ml}) \times$ fasting glucose $(\mathrm{mmol} / \mathrm{l})] / 22.5$. All subjects had provided written informed consent for participation in the study. The Chonnam National University Hospital Institutional Review Board approved this study.

\section{Statistical analyses}

The period of time before the follow-up examination was calculated as the interval between the baseline examination and re-examination. Baseline data are presented as means \pm standard deviation (SD) or percentages for categorical variables according to diabetes status at follow-up. Baseline differences in general and biochemical variables were compared using the $t$-test (Mann-Whitney U test for AST, ALT, GGT, TG and CRP) or chi-square test for categorical variables. Associations of liver enzymes with the incidence of type 2 diabetes were analyzed using logistic regression models. Analyses were performed separately for males and females. The levels of liver enzymes were divided into four groups, using sex-specific 25th, 50th, and 75th percentiles as cut-points: for AST, 21, 25, and $31 \mathrm{U} / \mathrm{L}$ in males and 19, 22, and $26 \mathrm{U} / \mathrm{L}$ in females; for ALT, 16, 21, and $30 \mathrm{U} / \mathrm{L}$ in males and 14, 17, and $22 \mathrm{U} / \mathrm{L}$ in females; for GGT, 20, 31, and $55 \mathrm{U} / \mathrm{L}$ in males and 13, 16, and $22 \mathrm{U} /$ $\mathrm{L}$ in females. Four models were constructed for each liver enzyme: the first model included age; the second model included all previous factors plus BMI, WC, TC, HDL-C, log TG, alcohol intake status, smoking status, 
physical activity, and follow-up period; the third model included all previous factors plus log CRP; and the fourth model included all previous factors plus fasting glucose and the HOMA value. Because the distributions of AST, ALT, GGT, TG and CRP were skewed, we logtransformed these values prior to inclusion in a logistic regression model. Interactions of ALT and GGT with BMI, WC, and alcohol intake status were estimated using a logistic regression model. Linear trends were evaluated using logistic regression with the AST, ALT, and GGT categories as continuous variables. Results are presented as odds ratios (ORs) and 95\% confidence intervals $(\mathrm{CIs})$. A value of $\mathrm{p}<0.05$ was taken to indicate statistical significance. All statistical analyses were performed using PASW statistics 21 (SPSS Inc., Chicago, IL, USA).

\section{Results}

\section{Baseline characteristics of subjects}

Baseline characteristics of the study population according to incident diabetes status at the follow-up examination are shown in Tables 1 and 2. During the median follow-up period of 4.2 years (range 3.5 to 8.0 years), 548 subjects (235 males and 313 females) were newly identified as having type 2 diabetes.

Compared to subjects who did not develop diabetes, subjects of both sexes who developed type 2 diabetes had higher BMI and WC; higher concentrations of ALT,

Table 1 Baseline characteristics of males subjects

\begin{tabular}{|c|c|c|c|}
\hline \multirow[t]{2}{*}{ Variables } & \multicolumn{3}{|c|}{ Males $(n=2,603)$} \\
\hline & Diabetes $\ddagger$ & Non-diabetes & $p$-value ${ }^{*}$ \\
\hline Age (years) & $62.4(7.8)$ & $62.4(7.5)$ & 0.848 \\
\hline Body mass index $\left(\mathrm{kg} / \mathrm{m}^{2}\right)$ & $24.6(2.9)$ & $23.7(2.7)$ & $<0.001$ \\
\hline Waist circumference $(\mathrm{cm})$ & $87.1(7.6)$ & $84.7(7.6)$ & $<0.001$ \\
\hline AST (units/l) & $26(21-32)$ & $25(21-30)$ & 0.089 \\
\hline ALT (units/l) & $24(18-34)$ & $21(16-29)$ & $<0.001$ \\
\hline GGT (units/l) & $39(24-74)$ & $30(19-53)$ & 0.006 \\
\hline Fasting glucose (mg/dl) & $108.3(13.8)$ & $100.1(9.7)$ & $<0.001$ \\
\hline HOMA (\%) & $1.54(1.10)$ & $1.14(1.13)$ & $<0.001$ \\
\hline Total cholesterol (mg/dl) & $183.6(35.9)$ & $182.8(34.1)$ & 0.658 \\
\hline HDL cholesterol (mg/dl) & $45.5(11.7)$ & $47.2(12.3)$ & 0.045 \\
\hline Triglycerides (mg/dl) & $152(107-231)$ & $128(88-194)$ & 0.002 \\
\hline C-reactive protein (mg/dl) & $0.08(0.04-0.17)$ & $0.07(0.03-0.16)$ & 0.757 \\
\hline Current drinker (\%) & $151(64.3)$ & $1,577(66.7)$ & 0.490 \\
\hline Current smoker (\%) & $81(34.5)$ & 748 (31.6) & 0.548 \\
\hline Physical exercise (\%) & $87(37.0)$ & $819(34.7)$ & 0.474 \\
\hline \multicolumn{4}{|c|}{$\begin{array}{l}\text { Data are means (SD), medians (interquartile ranges; } 25 \text { th-75th) for skewed } \\
\text { variables, or proportions for categorical variables. *Differences were assessed } \\
\text { using } t \text {-tests (for continuous variables) or chi-square tests (for categorical } \\
\text { variables); Mann-Whitney tests were performed for the following skewed } \\
\text { variables: AST, ALT, GGT, triglycerides and c-reactive protein. } \\
\text { ₹ Diabetes status at follow-up examination. }\end{array}$} \\
\hline
\end{tabular}

Table 2 Baseline characteristics of females subjects

\begin{tabular}{lccc}
\hline Variables & \multicolumn{3}{c}{ Females (n= 4,323) } \\
\cline { 2 - 4 } & Diabetes ₹ & Non-diabetes & $\boldsymbol{p}$-value* \\
\hline Age (years) & $61.7(6.9)$ & $60.8(7.7)$ & 0.049 \\
Body mass index (kg/m²) & $26.1(3.9)$ & $24.5(3.2)$ & $<0.001$ \\
Waist circumference (cm) & $89.3(8.7)$ & $85.8(8.7)$ & $<0.001$ \\
AST (units/l) & $23(19-27)$ & $22(19-26)$ & 0.076 \\
ALT (units/l) & $20(14-26)$ & $16(13-21)$ & $<0.001$ \\
GGT (units/l) & $20(15-31)$ & $15(12-21)$ & $<0.001$ \\
Fasting glucose (mg/dl) & $106.8(9.6)$ & $96.5(9.2)$ & $<0.001$ \\
HOMA (\%) & $1.74(1.05)$ & $1.31(0.96)$ & $<0.001$ \\
Total cholesterol (mg/dl) & $200.2(36.2)$ & $192.9(36.7)$ & 0.001 \\
HDL cholesterol (mg/dl) & $45.8(10.9)$ & $48.6(11.7)$ & $<0.001$ \\
Triglycerides (mg/dl) & $161(113-243.5)$ & $123(86-177)$ & $<0.001$ \\
C-reactive protein (mg/dl) & $0.09(0.04-0.20)$ & $0.05(0.02-0.11)$ & 0.444 \\
Current drinker (\%) & $109(34.8)$ & $1,454(36.3)$ & 0.112 \\
Current smoker (\%) & $11(3.5)$ & $110(2.7)$ & 0.317 \\
Physical exercise (\%) & $100(31.9)$ & $1,242(31.0)$ & 0.730 \\
\hline
\end{tabular}

Data are means (SD), medians (interquartile ranges; 25th-75th) for skewed variables, or proportions for categorical variables. *Differences were assessed using $t$-tests (for continuous variables) or chi-square tests (for categorical variables); Mann-Whitney tests were performed for the following skewed variables: AST, ALT, GGT, triglycerides and c-reactive protein. ₹ Diabetes status at follow-up examination.

GGT; higher fasting glucose levels, HOMA indices, and TG; and lower levels of HDL-C. Although levels of liver enzymes were within the normal range, subjects of both sexes who developed type 2 diabetes had higher concentrations of ALT, and GGT than subjects who did not develop diabetes. AST and CRP were slightly higher in those of both sexes with diabetes; however, the difference was not significant in either sex.

\section{AST and incidence of type 2 diabetes}

There was no linear relationship between AST and incidence of type 2 diabetes. The ORs for incidence of diabetes according to AST quartile were 0.98 (0.63-1.52), 0.93 (0.61-1.43), and $1.07(0.69-1.66)$ in males and 0.67 (0.45-0.99), 0.83 (0.57-1.12), and $0.95(0.66-1.37)$ in females after adjusting for age, BMI, WC, TC, HDL-C, log-TG, alcohol intake status, smoking status, physical activity, follow-up period, log-CRP, fasting glucose, and HOMA indices (Tables 3 and 4).

\section{ALT and incidence of type 2 diabetes}

After adjusting for age, BMI, WC, TC, HDL-C, log-TG, alcohol intake status, smoking status, physical activity, follow-up period, and log-CRP, the ORs for incidence of diabetes according to ALT quartile were 1.53, 2.24, and 2.31 in males and 0.97, 1.38, and 1.86 in females (Tables 3 and 4). Further adjustment for fasting glucose and HOMA indices attenuated the association; however, 
Table 3 Adjusted odds ratio (95\% confidence interval) for 4-years incidence of type 2 diabetes according to quartile groups of liver enzymes (AST, ALT, and GGT) at baseline in males

\begin{tabular}{|c|c|c|c|c|c|}
\hline & Q1 & Q2 & Q3 & Q4 & $P$ for trend \\
\hline AST (units/l) & $\leq 20$ & 21 to 24 & 25 to 30 & $\geq 31$ & \\
\hline Cases/persons at risk & $49 / 620$ & $56 / 656$ & $64 / 687$ & $66 / 640$ & \\
\hline Model 1 & 1 & $1.09(0.73-1.62)$ & $1.20(0.81-1.77)$ & $1.34(0.91-1.98)$ & 0.116 \\
\hline Model 2 & 1 & $1.11(0.74-1.66)$ & $1.10(0.74-1.65)$ & $1.21(0.80-1.83)$ & 0.390 \\
\hline Model 3 & 1 & $1.12(0.73-1.71)$ & $1.09(0.72-1.65)$ & $1.15(0.76-1.76)$ & 0.565 \\
\hline Model 4 & 1 & $0.98(0.63-1.52)$ & $0.93(0.61-1.43)$ & $1.07(0.69-1.66)$ & 0.794 \\
\hline ALT (units/l) & $\leq 15$ & 16 to 20 & 21 to 29 & $\geq 30$ & \\
\hline Cases/persons at risk & $31 / 615$ & $46 / 632$ & $81 / 710$ & $77 / 646$ & \\
\hline Model 1 & 1 & $1.49(0.93-2.39)$ & $2.49(1.62-3.83)$ & $2.67(1.72-4.15)$ & $<0.001$ \\
\hline Model 2 & 1 & $1.42(0.89-2.28)$ & $2.19(1.41-3.41)$ & $2.11(1.33-3.35)$ & $<0.001$ \\
\hline Model 3 & 1 & $1.53(0.93-2.52)$ & $2.24(1.40-3.59)$ & $2.31(1.42-3.75)$ & $<0.001$ \\
\hline Model 4 & 1 & $1.36(0.82-2.27)$ & $2.03(1.26-3.29)$ & $1.95(1.18-3.21)$ & 0.004 \\
\hline GGT (units/l) & $\leq 19$ & 20 to 30 & 31 to 54 & $\geq 55$ & \\
\hline Cases/persons at risk & $38 / 661$ & $44 / 651$ & $72 / 635$ & $81 / 656$ & \\
\hline Model 1 & 1 & $1.20(0.77-1.89)$ & $2.14(1.42-3.23)$ & $2.38(1.59-3.57)$ & $<0.001$ \\
\hline Model 2 & 1 & $1.09(0.69-1.73)$ & $2.00(1.28-3.12)$ & $2.13(1.33-3.41)$ & $<0.001$ \\
\hline Model 3 & 1 & $1.00(0.62-1.63)$ & $1.86(1.17-2.96)$ & $1.97(1.21-3.22)$ & 0.001 \\
\hline Model 4 & 1 & $0.86(0.52-1.42)$ & $1.57(0.97-2.54)$ & $1.58(0.95-2.63)$ & 0.011 \\
\hline
\end{tabular}

Model 1: adjusted for age.

Model 2: Model 1 plus body mass index, waist circumference, total cholesterol, HDL-cholesterol, log-triglyceride, alcohol intake status, smoking status, physical activity, and follow-up period.

Model 3: Model 2 plus log-CRP.

Model 4: Model 3 plus fasting glucose and HOMA

ALT remained a significant risk factor in both sexes. Comparison of the highest versus the lowest quartiles for ALT showed ORs for incidence of type 2 diabetes of 1.95 (95\% CI: 1.18-3.21) in males and 1.49 (95\% CI: 1.032.16) in females. Interactions of ALT with alcohol intake status, BMI and WC were not significant in either sex (data not shown).

\section{GGT and incidence of type 2 diabetes}

According to all models, there was a positive linear relationship between GGT and incidence of type 2 diabetes in both sexes (Tables 3 and 4). After adjusting for age, BMI, WC, TC, HCL-C, log-TG, alcohol intake status, smoking status, physical activity, follow-up period, and $\log$-CRP, the ORs for incidence of diabetes according to GGT quartile were 1.00, 1.86, and 1.97 in males and 1.11, 1.60, and 2.45 in females (Tables 3 and 4). Further adjustment for fasting glucose and HOMA indices attenuated the association; however, GGT remained a significant risk factor in females. When the fourth quartile of GGT was compared with the first quartile, ORs for incidence of diabetes were 1.58 (95\% CI: 0.95-2.63) in males and 1.85 (95\% CI: 1.23-2.79) in females. Interactions of GGT with alcohol intake status, BMI and WC were not significant in either sex (data not shown).

\section{Discussion}

This study examined the associations of serum liver enzymes on the incidence of type 2 diabetes in a prospective study of a general Korean population. Our results suggest that serum ALT and GGT were positively associated with an increased risk of type 2 diabetes in both sexes, and no interactions were seen between ALT or GGT and alcohol intake status, BMI, or WC. After adjustment for potential confounders, we found that elevated levels of ALT were independently associated with type 2 diabetes in both sexes, with an independent association for GGT only in females.

In the present study, after adjusting for diabetes risk factors, the association between AST and incidence of diabetes was not significant in either sex. Our results are consistent with those reported by Nakanishi et al. [21], who found no association of AST with diabetes risk after adjustment for age, family history of diabetes, BMI, alcohol intake, cigarette smoking, physical activity, systolic blood pressure, lipid profile, fasting glucose, and white blood cell count in a study of male Japanese office workers. In contrast, in the prospective The Insulin Resistance Atherosclerosis Study, Hanley et al. [5] reported that AST independently predicted type 2 diabetes after adjustment for covariates, including metabolic syndrome 
Table 4 Adjusted odds ratio (95\% confidence interval) for 4-years incidence of type 2 diabetes according to quartile groups of liver enzymes (AST, ALT, and GGT) at baseline in females

\begin{tabular}{|c|c|c|c|c|c|}
\hline & Q1 & Q2 & Q3 & Q4 & $P$ for trend \\
\hline AST (units/l) & $\leq 18$ & 19 to 21 & 22 to 25 & $\geq 26$ & \\
\hline Cases/persons at risk & 74/983 & $58 / 1,066$ & $86 / 1,187$ & $95 / 1,104$ & \\
\hline Model 1 & 1 & $0.69(0.48-0.98)$ & $0.92(0.67-1.28)$ & $1.11(0.80-1.52)$ & 0.212 \\
\hline Model 2 & 1 & $0.66(0.46-0.95)$ & $0.87(0.62-1.22)$ & $0.99(0.71-1.38)$ & 0.567 \\
\hline Model 3 & 1 & $0.72(0.49-1.05)$ & $0.88(0.62-1.25)$ & $1.01(0.72-1.43)$ & 0.562 \\
\hline Model 4 & 1 & $0.67(0.45-0.99)$ & $0.83(0.57-1.12)$ & $0.95(0.66-1.37)$ & 0.783 \\
\hline ALT (units/l) & $\leq 13$ & 14 to 16 & 17 to 21 & $\geq 22$ & \\
\hline Cases/persons at risk & $56 / 1,199$ & $52 / 994$ & $77 / 1,003$ & $128 / 1,127$ & \\
\hline Model 1 & 1 & $1.12(0.76-1.65)$ & $1.69(1.18-2.40)$ & $2.65(1.91-3.67)$ & $<0.001$ \\
\hline Model 2 & 1 & $0.99(0.67-1.47)$ & $1.40(0.97-2.01)$ & $1.86(1.32-2.61)$ & $<0.001$ \\
\hline Model 3 & 1 & $0.97(0.64-1.48)$ & $1.38(0.94-2.02)$ & $1.86(1.31-2.65)$ & $<0.001$ \\
\hline Model 4 & 1 & $0.86(0.56-1.32)$ & $1.23(0.83-1.83)$ & $1.49(1.03-2.16)$ & 0.006 \\
\hline GGT (units/l) & $\leq 12$ & 13 to 15 & 16 to 21 & $\geq 22$ & \\
\hline Cases/persons at risk & $45 / 1,248$ & $42 / 882$ & $85 / 1,076$ & $141 / 1,117$ & \\
\hline Model 1 & 1 & $1.35(0.88-2.07)$ & $2.30(1.59-3.33)$ & $3.88(2.74-5.49)$ & $<0.001$ \\
\hline Model 2 & 1 & $1.14(0.74-1.77)$ & $1.73(1.18-2.54)$ & $2.69(1.86-3.89)$ & $<0.001$ \\
\hline Model 3 & 1 & $1.11(0.70-1.76)$ & $1.60(1.06-2.39)$ & $2.45(1.66-3.61)$ & $<0.001$ \\
\hline Model 4 & 1 & $0.97(0.60-1.55)$ & $1.27(0.83-1.94)$ & $1.85(1.23-2.79)$ & $<0.001$ \\
\hline
\end{tabular}

Model 1: adjusted for age.

Model 2: Model 1 plus body mass index, waist circumference, total cholesterol, HDL-cholesterol, log-triglyceride, alcohol intake status, smoking status, physical activity, and follow-up period.

Model 3: Model 2 plus log-CRP.

Model 4: Model 3 plus fasting glucose and HOMA

variables, directly measured insulin sensitivity, acute insulin response, and CRP. The OR of type 2 diabetes for the highest versus the lowest quartiles was 1.98 (95\% CI: 1.233.17). Although AST is a marker of hepatocellular health, it is a less specific marker of liver function than ALT and GGT [4]. Therefore, AST may be a less specific marker of liver pathology related to development of type 2 diabetes.

Some prospective studies $[5,8,10,11,13,14,24]$ have reported that higher ALT concentrations predicted development of type 2 diabetes. Our data also indicated that ALT was an independent association in both sexes after adjusting for other diabetes risk factors. In the late 1980s, Ohlson et al. [25] reported that baseline ALT was a predictor of the incidence of type 2 diabetes after 13.5 years of follow-up in a cohort of 766 Swedish males, with a significant fourfold increased risk for males in the upper quintile compared to the lowest quintile.

Serum GGT has been widely used as an index of liver dysfunction and as a biological marker of alcohol abuse $[17,21,26]$. Most previous studies [3,4,6,7,10,12,14,16-20] reported an association of GGT concentrations with the incidence of type 2 diabetes, and our results are in agreement with these findings. A 4-year follow-up prospective cohort study in a Korean population [4] showed a strong dose-response relationship between the serum
GGT concentration at baseline and the incidence of type 2 diabetes. However, two studies reported no association of GGT concentration with the development of type 2 diabetes $[8,25]$. In a longitudinal study of Pima Indians [8], despite a strong correlation between ALT and GGT concentrations, only ALT was positively associated with the risk of type 2 diabetes. In the Pima Indian study, alcohol consumption was not evaluated, which could have obscured the association between GGT and development of type 2 diabetes. In our study, as in others, the association of GGT with the incidence of type 2 diabetes was independent of alcohol consumption $[3,4,6,17,18,21]$.

Although the mechanism underlying the associations between liver enzymes and incidence of type 2 diabetes remains unclear, some possibilities can be considered. One is that increased serum AST, ALT, and GGT levels reflect an excess deposit of fat in the liver, a condition known as non-alcoholic fatty liver disease (NAFLD). NAFLD is considered a hepatic manifestation of metabolic syndrome, which refers to a cluster of cardiovascular risk factors associated with insulin resistance, including central obesity, hypertension, dyslipidemia, and type 2 diabetes [27]. NAFLD, which is closely related to obesity and visceral fat deposition, is now regarded as a feature of insulin resistance syndrome [2], and visceral 
adipose tissue is known to confer a significantly higher risk of type 2 diabetes [28]. Excess visceral fat accumulation may be causally related to features of insulin resistance as well as to high plasma levels of insulin and glucose $[29,30]$. Overt diabetes is thought to be preceded by a long period of insulin resistance, during which blood glucose is maintained at a near-normal level by compensatory hyperinsulinemia [31]. In this study, ALT concentrations were independently associated with the incidence of type 2 diabetes in both sexes, after adjusting for HOMA as a marker of insulin resistance and fasting glucose, whereas GGT was independently associated only in females.

A second possibility is that GGT plays an important role in antioxidant systems, with the primary function of maintaining intracellular glutathione levels, a major intracellular antioxidant defense for the cell [32-34]. Increased oxidative stress contributes to the development and progression of diabetes $[35,36]$ and chronic oxidative stress results in decreased responsiveness to insulin, ultimately leading to type 2 diabetes [30]. Although the mechanism remains largely unknown, there is clear evidence that cellular GGT concentration is closely related to oxidative stress indicators in vivo [37-39]. Inflammation has also been recognized as a manifestation of oxidative stress, and all pathways that generate mediators of inflammation, such as adhesion molecules and interleukins, are induced by oxidative stress [40]. Several prospective studies have demonstrated that elevated CRP levels were significantly predictive of risk of type 2 diabetes [41-46]. Changes in inflammation that occur through oxidative stress are assumed to be a common step in the pathogenesis of type 2 diabetes. In the present study, after adjusting for CRP as a marker of inflammation and/or oxidative stress, GGT was found to be a significantly associated with the incidence of diabetes in both sexes. These results suggested that the association was independent of inflammation and oxidative stress.

The present study had the following limitation. We were unable to complete follow-up examinations for all participants who were still alive at the time of reexamination, which may have introduced a selection bias.

The strengths of this study relate primarily to its prospective design, with inclusion of a large sample size and availability of data on lifestyles and diabetes risk factors. Second, in contrast to most other prospective studies, in which the diagnosis of diabetes was based only on selfreporting, the diagnosis of diabetes in the present study was based on both self-reporting and biological markers. Third, we used relevant information to exclude subjects with various etiologies of liver pathology, such as viral hepatitis, liver cirrhosis, and liver cancer. Fourth, our study considered the HOMA index, which is a wellvalidated method for measurement of insulin resistance and has shown a moderate-to-strong correlation ( 0.58 to 0.88 ) with reference techniques, such as the euglycemic clamp [47].

\section{Conclusions}

In conclusion, in this prospective study, over a median period of 4.2 years and after adjusting for potential confounders, elevated serum ALT concentrations in both sexes and GGT only in females were independently associated with type 2 diabetes. The associations between these enzymes and incidence of type 2 diabetes were independent of insulin resistance, inflammation and/or oxidative stress markers. Although the mechanisms underpinning these associations require further investigation, these results support the hypothesis that the liver is important in the pathogenesis of type 2 diabetes and that hepatic enzymes may be useful additional markers of subjects at high risk for development of diabetes.

\section{Abbreviations}

AST: Aspartate aminotransferase; ALT: Alanine aminotransferase;

GGT: Gamma-glutamyltransferase; BMI: Body mass index; WC: Waist circumference; TC: Total cholesterol; HDL-C: High-density lipoprotein cholesterol; TG: Triglycerides (TG); CRP: C-reactive protein;

HOMA: Homeostasis model assessment; NAFLD: Non-alcoholic fatty liver disease.

\section{Competing interests}

The authors declare no competing interests.

\section{Authors' contributions}

$\mathrm{HR}$ prepared the study proposal, collected data in the field, analyzed the data and drafted the manuscript. SS and MH contributed to the study design, collected data in the field, assisted with the preparation of the proposal, and contributed to the manuscript. HS, KS, YH, and SK collected data in the field, interpretation of data and reviewed manuscript. JS interpretation of data and critically reviewed the manuscript. All authors read and approved the final manuscript.

\section{Acknowledgements}

This study was supported by Research Institute of Medical Sciences, Chonnam National University.

\section{Author details}

'Department of Preventive Medicine, Chonnam National University Medical School, 5, Hak-dong, Dong-gu, Gwangju 501-746, Korea. ${ }^{2}$ Department of Preventive Medicine and Public Health, School of Medicine, Chungnam National University, Daejun, Korea. ${ }^{3}$ Department of Preventive Medicine, College of Medicine, Seonam University, Namwon, Korea. ${ }^{4}$ Department of Preventive Medicine \& Institute of Wonkwang Medical Science, Wonkwang University school of Medicine, Iksan, Korea. ${ }^{5}$ Department of Neurology \& Research Institute of Clinical Medicine, Chonbuk National University Medical School \& Chonbuk National University Hospital, Jeonju, Korea.

Received: 30 October 2013 Accepted: 4 February 2014 Published: 6 February 2014

\section{References}

1. Duckworth WC, Hamel FG, Peavy DE: Hepatic metabolism of insulin. Am Med 1988, 85:71-76.

2. Marchesini G, Brizi M, Bianchi G, Tomassetti S, Bugianesi E, Lenzi M, McCullough AJ, Natale S, Forlani G, Melchionda N: Nonalcoholic fatty liver disease: a feature of the metabolic syndrome. Diabetes 2001, 50:1844-1850.

3. Lee DH, Silventoinen $K$, Jacobs DR, Jousilahti P, Tuomileto J: GammaGlutamyltransferase, obesity, and the risk of type 2 diabetes: 
observational cohort study among 20,158 middle-aged men and women. J Clin Endocrinol Metab 2004, 89:5410-5414.

4. Lee DH, Ha MH, Kim JH, Christiani DC, Gross MD, Steffes M, Blomhoff R, Jacobs DR Jr: Gamma-glutamyltransferase and diabetes-a 4 year follow-up study. Diabetologia 2003, 46:359-364.

5. Hanley AJ, Williams K, Festa A, Wagenknecht LE, D'Agostino RB Jr, Kempf J, Zinman B, Haffner SM: Elevations in markers of liver injury and risk of type 2 diabetes - The insulin resistance atherosclerosis study. Diabetes 2004, 53:2623-2632.

6. Nakanishi N, Suzuki K, Tatara K: Serum gamma-glutamyltransferase and risk of metabolic syndrome and type 2 diabetes in middle-aged Japanese men. Diabetes Care 2004, 27:1427-1432.

7. Andre P, Balkau B, Born C, Royer B, Wilpart E, Charles MA, Eschwege E: Hepatic markers and development of type 2 diabetes in middle aged men and women: a three-year follow-up study. The D.E.S.I.R. Study (Data from an Epidemiological Study on the Insulin Resistance syndrome). Diabetes Metab 2005, 31:542-550.

8. Vozarova B, Stefan N, Lindsay RS, Saremi A, Pratley RE, Bogardus C, Tataranni PA: High alanine aminotransferase is associated with decreased hepatic insulin sensitivity and predicts the development of type 2 diabetes. Diabetes 2002, 51:1889-1895.

9. Nannipieri M, Gonzales C, Baldi S, Posadas R, Williams K, Haffner SM, Stern MP, Ferrannini E: Liver enzymes, the metabolic syndrome, and incident diabetes: the Mexico City diabetes study. Diabetes Care 2005, 28:1757-1762

10. Doi $Y$, Kubo M, Yonemoto K, Ninomiya T, Iwase M, Tanizaki Y, Shikata K, lida $M$, Kiyohara $Y$ : Liver enzymes as a predictor for incident diabetes in a Japanese population: The Hisayama study. Obesity 2007, 15:1841-1850.

11. Goessling W, Massaro JM, Vasan RS, D'Agostino RB Sr, Ellison RC, Fox CS: Aminotransferase levels and 20-year risk of metabolic syndrome, diabetes, and cardiovascular disease. Gastroenterology 2008, 135:1935-1944.

12. Monami M, Bardini G, Lamanna C, Pala L, Cresci B, Francesconi P, Buiatti E, Rotella CM, Mannucci E: Liver enzymes and risk of diabetes and cardiovascular disease: Results of the Firenze Bagno a Ripoli (FIBAR) study. Metabolism 2008, 57:387-392.

13. Jiamjarasrangsi W, Sangwatanaroj S, Lohsoonthorn V, Lertmaharit S: Increased alanine aminotransferase level and future risk of type 2 diabetes and impaired fasting glucose among the employees in a university hospital in Thailand. Diabetes Metab 2008, 34:283-289.

14. Sato KK, Hayashi T, Nadamura Y: Liver enzymes compared with alcohol consumption in predicting the risk of type 2 diabetes. Diabetes Care 2008 31:1230-1236

15. Ford ES, Schulze MB, Bergmann MM, Thamer C, Joost HG, Boeing H: Liver enzymes and incident diabetes: findings from the European Prospective Investigation into Cancer and Nutrition (EPIC)-Potsdam Study. Diabetes Care 2008, 31:1138-1143

16. Wannamethee SG, Shaper AG, Lennon L, Whincup PH: Hepatic enzymes, the metabolic syndrome, and the risk of type 2 diabetes in older men. Diabetes Care 2005, 28:2913-2918.

17. Lee DH, Jacobs DR Jr, Gross M, Kiefe Cl, Roseman J, Lewis CE, Steffes M: Gamma-glutamyltransferase is a predictor of incident diabetes and hypertension: the Coronary Artery Risk Development in Young Adults (CARDIA) Study. Clin Chem 2003, 49:1358-1366.

18. Perry IJ, Wannamethee SG, Shaper AG: Prospective study of serum gamma-glutamyltransferase and risk of NIDDM. Diabetes Care 1998, 21:732-737.

19. Andre P, Balkau B, Born C, Charles MA, Eschwege E: Three-year increase of gamma-glutamyltransferase level and development of type 2 diabetes in middle-aged men and women: the D.E.S.I.R. cohort. Diabetologia 2006 49:2599-2603.

20. Meisinger $C$, Lowel $H$, Heier M, Schneider A, Torand B, KORA Study Group: Serum gamma-glutamyltransferase and risk of type 2 diabetes mellitus in men and women from the general population. J Intern Med 2005, 258:527-535.

21. Nakanishi N, Nishina K, Li W, Sato M, Suzuki K, Tatara K: Serum gammaglutamyltransferase and development of impaired fasting glucose or type 2 diabetes in middle-aged Japanese men. J Intern Med 2003, 254:287-295.

22. Kweon SS, Shin MH, Jeong SK, Nam HS, LEE YH, Park KS, Ryu SY, Choi SW, Kim BH, Rhee JA, Zheng W, Choi JS: Cohort profile: the Namwon study and the Dong-gu study. Int J Epidemiol 2013 [Epub ahead of print].
23. Matthews DR, Hosker JP, Rudenski AS, Naylor BA, Treacher DF, Turner RC: Homeostasis model assessment: insulin resistance and beta-cell function from fasting plasma glucose and insulin concentrations in man. Diabetologia 1985, 28:412-419.

24. Sattar N, Scherbakova O, Ford I, O'Reilly DS, Stanley A, Forrest E, Macfarlane PW, Packard CJ, Cobbe SM, Shepherd J: Elevated alanine aminotransferase predicts new-onset type 2 diabetes independently of classical risk factors, metabolic syndrome, and C-reactive protein in the west of Scotland coronary prevention study. Diabetes 2004, 53:2855-2860.

25. Ohlson LO, Larsson B, Bjorntorp P, Eriksson H, Svardsudd K, Welin L, Tibblin $G$, Wilhelmsen L: Risk factors for type 2 (non-insulin-dependent) diabetes mellitus. Thirteen and one-half years of follow-up of the participants in a study of Swedish men born in 1913. Diabetologia 1988, 31:798-805.

26. Conigrave KM, Degenhardt LJ, Whitfield JB, Saunders JB, Helander A, Tabakoff B: CDT, GGT, and AST as markers of alcohol use: the WHO/ISBRA collaborative project. Alcohol Clin Exp Res 2002, 26:332-339.

27. Finelli C, Tarantino $\mathrm{G}$ : What is the role of adiponectin in obesity related non-alcoholic fatty liver disease? World J Gastroenterol 2013, 19:802-812.

28. Tarantino G, Capone D: Inhibition of the mTOR pathway: A possible protective role in coronary artery disease. Ann Med 2013, 45:348-356.

29. Finelli C, Tarantino G: What about non-alcoholic fatty liver disease as a new criterion to define metabolic syndrome? World J Gastroenterol 2013, 19:3375-3384

30. Caputi A, Tarantino G: JNKs, insulin resistance and inflammation: A possible link between NAFLD and coronary artery disease. World J Gastroenterol 2011, 17:3785-3794

31. Kahn SE: The relative contributions of insulin resistance and beta-cell dysfunction to the pathophysiology of type 2 diabetes. Diabetologia 2003, 46:3-19.

32. Takahashi Y, Oakes SM, Williams MC, Takahashi S, Miura T, Joyce-Brady M: Nitrogen dioxide exposure activates gamma-glutamyl transferase gene expression in rat lung. Toxicol Appl Pharmacol 1997, 143:388-396.

33. Kugelman A, Choy HA, Liu R, Shi MM, Gozal E, Forman HJ: GammaGlutamyl transpeptidase is increased by oxidative stress in rat alveolar L2 epithelial cells. Am J Respir Cell Mol Biol 1994, 11:586-592.

34. Karp DR, Shimooku K, Lipsky PE: Expression of gamma-glutamyl transpeptidase protects ramos $B$ cells from oxidation-induced cell death. J Biol Chem 2001, 276:3798-3804.

35. Ceriello A: Oxidative stress and glycemic regulation. Metabolism 2000, 49:27-29.

36. Baynes JW, Thorpe SR: Role of oxidative stress in diabetic complications: a new perspective on an old paradigm. Diabetes 1999, 48:1-9.

37. Stark AA, Russell JJ, Langenbach R, Pagano DA, Zeiger E, Huberman E: Localization of oxidative damage by a glutathione-gammaglutamyltranspeptidase system in preneoplastic lesions in sections of livers from carcinogen-treated rats. Carcinogenesis 1994, 15:343-348.

38. Paolicchi A, Tongiani R, Tonarelli P, Comporti M, Pompella A: Gammaglutamyltranspeptidase-dependent lipid peroxidation in isolated hepatocytes and HepG2 hepatoma cells. Free Radic Biol Med 1997, 22:853-860.

39. Drozdz R, Parmentier C, Hachad H, Leroy P, Siest G, Wellman M: Gammaglutamyltransferase dependent generation of reactive oxygen species from a glutathione/transferrin system. Free Radic Biol Med 1998, 25:786-792.

40. Roebuck KA: Oxidant stress regulation of IL-8 and ICAM-1 gene expression: differential activation and binding of the transcription factors AP- 1 and NF-kappaB (Review). Int J Mol Med 1999, 4:223-230.

41. Nakanishi S, Yamane K, Kamei N, Okubo M, Kohno N: Elevated C-reactive protein is a risk factor for the development of type 2 diabetes in Japanese Americans. Diabetes Care 2003, 26:2754-2757.

42. Doi Y, Kiyohara Y, Kubo M, Ninomiya T, Wakugawa Y, Yonemoto K, Iwase M: Elevated C-reactive protein is a predictor of the development of diabetes in a general Japanese population: the Hisayama Study. Diabetes Care 2005, 28:2497-2500.

43. Pradhan AD, Manson JE, Rifai N, Buring JE, Ridker PM: C-reactive protein, interleukin 6, and risk of developing type 2 diabetes mellitus. JAMA 2001, 286:327-334.

44. Barzilay Jl, Abraham L, Heckbert SR, Cushman M, Kuller LH, Resnick HE, Tracy RP: The relation of markers of inflammation to the development of glucose disorders in the elderly: the Cardiovascular Health Study. Diabetes 2001, 50:2384-2389. 
45. Freeman DJ, Norrie J, Caslake MJ, Gaw A, Ford I, Lowe GD, O'Reilly DS, Packard CJ, Sattar N: C-reactive protein is an independent predictor of risk for the development of diabetes in the West of Scotland Coronary Prevention Study. Diabetes 2002, 51:1596-1600.

46. Spranger J, Kroke A, Mohlig M, Hoffmann K, Bergmann MM, Ristow M, Boeing H, Pfeiffer AF: Inflammatory cytokines and the risk to develop type 2 diabetes: results of the prospective population-based European Prospective Investigation into Cancer and Nutrition (EPIC)-Potsdam Study. Diabetes 2003, 52:812-817.

47. Wallace TM, Levy JC, Matthews DR: Use and abuse of HOMA modeling. Diabetes Care 2004, 27:1487-1495.

doi:10.1186/1758-5996-6-14

Cite this article as: Ahn et al:: The association between liver enzymes and risk of type 2 diabetes: the Namwon study. Diabetology \& Metabolic Syndrome 2014 6:14.

\section{Submit your next manuscript to BioMed Central and take full advantage of:}

- Convenient online submission

- Thorough peer review

- No space constraints or color figure charges

- Immediate publication on acceptance

- Inclusion in PubMed, CAS, Scopus and Google Scholar

- Research which is freely available for redistribution 